\title{
“Antiscience Zealotry"? Values, Epistemic Risk, and the GMO Debate
}

Justin B. Biddle

School of Public Policy

Georgia Institute of Technology

685 Cherry Street

Atlanta, Georgia 30332 USA

Email: justin.biddle@pubpolicy.gatech.edu

\begin{abstract}
This paper argues that the controversy over GM crops is not best understood in terms of the supposed bias, dishonesty, irrationality, or ignorance on the part of proponents or critics, but rather in terms of differences in values. To do this, the paper draws upon and extends recent work of the role of values and interests in science, focusing particularly on inductive risk and epistemic risk, and it shows how the GMO debate can help to further our understanding of the various epistemic risks that are present in science and how these risks might be managed.
\end{abstract}

Acknowledgments. A preliminary version of this paper was presented the 2017 Conference on Values in Medicine, Science, and Technology at the University of Texas at Dallas. Thanks to the conference participants and to two anonymous reviewers for their valuable feedback.

Keywords. Values in science; inductive risk; disagreement; framing; philosophy of science in practice 
1. Introduction. The controversy over genetically modified organisms (GMOs) is intense and highly polarized. ${ }^{1}$ While the numerous polls of public attitudes show consistently that there is significant disagreement over the risks and benefits of GM crops (e.g., Pew Research Center 2016), they do not evince just how polarized the debate has become. Perhaps more helpful in illustrating the depth of the disagreement is the following: while some critics of GM crops feel strongly enough to organize or march in worldwide March Against Monsanto protests or even to destroy field trials (as Philippine activists did in $2013^{2}$ ), some proponents of GM crops feel sufficiently passionate to accuse those same critics of crimes against humanity-simply for criticizing the technology. In a well-publicized letter in support of GM crops, 123 Nobel Laureates characterize those who oppose GMOs not merely as misguided or incorrect, but as irrational and immoral, concluding their letter as follows: "Opposition based on emotion and dogma contradicted by data must be stopped. How many poor people in the world must die before we consider this a crime against humanity?" (emphasis in original). ${ }^{3}$ The claim that critics are acting reprehensibly simply by criticizing GMOs is not uncommon; to take one other prominent example, Norman Borlaug - the Nobel Peace Prize winner and so-called "father of the Green Revolution" - castigates critics for their "antiscience zealotry" and suggests that they are responsible for the world hunger that could have been prevented by these purportedly lifesaving technologies, had their development and/or dissemination not been impeded by irresponsible attacks (Borlaug 2000).

Both sides in the controversy over GM crops often dismiss the other as ignorant, biased, irrational, or dishonest. Critics of GMOs often dismiss the arguments of proponents due to their supposed biases -in particular, pro-industry bias due to financial ties to seed companies or other financially-interested entities ${ }^{4}$. Proponents often dismiss the views of critics because of their supposed ignorance, irrationality, or "anti-scientific" views. The "anti-science" or "war on science" narrative has become especially popular among science journalists. For example, in his essay "The Liberals' War on Science," Michael Shermer cites the GMO debate as evidence that the political left is just as anti-science as the political right (Shermer 2013). In a response to Shermer, Chris Mooney denies that liberals are just as anti-science as conservatives by arguing that anti-GMO views are not restricted to the political left, but he maintains the assumption that most critics of GMOs are anti-science (Mooney 2014). ${ }^{5}$ Even some philosophers of science tend to slide into an anti-science narrative. For example, in his discussion of the GMO debate in Science in a Democratic Society, Philip Kitcher suggests that those who are skeptical of the

\footnotetext{
${ }^{1}$ By 'GMOs,' I mean organisms created through the use of recombinant DNA technologies.

${ }^{2}$ See, for example, Kupferschmidt (2013).

${ }^{3}$ http://supportprecisionagriculture.org/nobel-laureate-gmo-letter rjr.html. Accessed July 30, 2016.

${ }^{4}$ This is a common criticism put forward by March Against Monsanto (http://www.marchagainst-monsanto.com). Accessed March 28, 2017.
}

${ }^{5}$ Mooney draws on work by Lewandowsky et al. (2013) to argue that conservatives are just as likely to be skeptical of GMOs as are liberals. To be fair, Mooney is less dogmatic in his treatment of GMO critics than is Shermer, but he still suggests that those who question the safety of GMOs are anti-science. 
safety of GM crops are, at the very least, ignorant of the relevant science-though he does acknowledge that there might be legitimate reasons to worry about the socio-economic impacts of GM crops (Kitcher 2011, Ch. 9).

While there is no question that some opponents of GMOs are biased or ignorant of the relevant facts, the blanket tendency to characterize critics as anti-science or engaged in a war on science is both misguided and dangerous. It is misguided because, as I will argue in this paper, the controversy over GM crops is not best understood in terms of the supposed bias, dishonesty, irrationality, or ignorance on the part of proponents or critics, but rather in terms of differences in values. Decisions to research, develop, and disseminate particular agriculture technologies have important social, economic, and cultural consequences for a wide range of stakeholders, and if we are to make progress in the debate over GM crops, it is essential that thoughtful communication about the impacts of values and interests on these decisions be promoted. Unfortunately, anti-science or war-on-science narratives do exactly the opposite. ${ }^{6}$

The aim of this paper is to argue that much of the controversy over GM crops should be understood in terms of differences in values-or, more specifically, in terms of differences in how associated epistemic risks are managed, including what I will call "framing risks" and "power risks." I begin (in Section 2) by reviewing relevant literature on the role of values and interests in science, focusing particularly on epistemic risk (Biddle 2016; Biddle and Kukla 2017). This work builds on recent literature on inductive risk by arguing that there are numerous decisions and activities in science that presuppose value judgments; some of these are adequately characterized as inductive risks, but many are not. Following this, I examine two points of contention in the GMO debate-how the GMO problem should be framed (Section 3) and whether there are significant health and safety risks of some GMOs (Section 4)-and argue that, in both of these cases, there are important epistemic risks (framing risks and power risks, respectively) that are managed in light of values and interests. These sections aim both to improve our understanding of the GMO controversy and to advance our understanding of the role of values and interests in science. I conclude the paper with some reflections on different types of disagreement, including "deep disagreement" and what I call "dirty disagreement."

Before proceeding, the argument should be qualified in three ways. First, the aim of this paper is not to defend a for or against position with respect to GM crops. GM crops-including herbicide tolerant crops, pesticide producing crops, and crops that are modified to enhance nutritional content (such as "Golden Rice") - are very different from one another, and there are good reasons to believe that any attempt to evaluate all such crops as a class is doomed to fail. Individual agricultural technologies should be evaluated on the basis of their consequences for health, environment, and society-whether they are GM or not (Biddle 2017; NASEM 2016; NRC 2002; Nuffield Council on Bioethics 1999, 2003). Rather than defending a pro or con

\footnotetext{
${ }^{6}$ A number of other commentators have developed similar arguments. Millstein (2015) argues for a similar conclusion with regard to GM crops, though her argument proceeds along different lines. Goldenberg (2016) and Navin (2016) develop similar arguments in the context of vaccine research. What is distinctive about the argument of the present paper is the way in which it both draws on and extends recent work in science and values, particularly on inductive and epistemic risk.
} 
position, the paper aims to deepen our understanding of the disagreement and do so in a way that will hopefully open up spaces for improved communication and mutual understanding.

Second, in arguing that the controversy over GM crops is not best understood in terms of bias, dishonesty, irrationality, or ignorance, I am (of course) not arguing that all participants in the debate always act rationally. Every debate includes participants who do not always exhibit canons of rationality and who argue for conclusions that are not based on evidence; this is especially true in the GM debate, where emotions run high and arguments are heated. In arguing that the controversy is best understood in terms of differences in values, I am arguing that the debate includes much space for rational disagreement-that the evidence alone might not settle the question of whether one should be supportive or critical of a particular GM crop, or even how we should characterize the risks of that crop-and that in many cases the disagreements between participants are based on differences in values. These value differences influence not just which questions participants take to be important (for example, human health versus socio-economic impacts) but also the criteria according to which these questions are answered. Thus, for example, values affect how participants define what "safety" means and what sorts of evidence are sufficient to determine whether a technology is sufficiently safe.

Finally, in this paper I will restrict my examination to questions about the risks of GM crops-including risks to human health and environment and socio-economic risks. There is, of course, a vigorous debate over the policy question of whether or not GMOs should be labeled as such, but I will ignore this issue here, focusing instead on scientific questions of risk assessment.

2. Values in Science. It is uncontroversial that science is a value-laden activity. Not only do value judgments legitimately influence which research projects are investigated, how experiments are conducted, and how research results are applied, they also legitimately influence hypothesis appraisal. This much has been clear at least since Thomas Kuhn's attempt to articulate the "shared criteria" of theory assessment, which he identifies as accuracy, consistency (internal and external), scope, simplicity, and fruitfulness. These criteria, he argues, function not as rules but rather as norms or values (Kuhn 1977, 330). In particular, they can be interpreted in different ways, and they can be weighted differently with respect to one another. Scientists may (for example) legitimately interpret the criteria of simplicity and even accuracy in different ways; moreover, scientists often prioritize these criteria differently, some (for example) valuing simplicity or mathematical elegance very highly, others valuing accuracy more highly. ${ }^{7}$ How scientists interpret and weigh these criteria is itself reflective of values. The upshot of this is that scientists can rationally disagree with one another in their assessment of

\footnotetext{
${ }^{7}$ Philosophers differ on the question of whether Kuhn's list of values (or something similar to it) is, in fact, the shared criteria of theory assessment; Ernan McMullin (1983) articulates a list that is similar to Kuhn's, while Helen Longino (1996) defends a very different list. I doubt very much that there is a single correct list, though I will not argue for this claim here. What is relevant is that, whatever the criteria are, they function as values in the sense that they can be interpreted differently and weighted differently with respect to one another.
} 
theories by adopting different interpretations of, or weighting schemes for, criteria for theory evaluation.

Most philosophers of science who examine the roles of values and interests in science go much further than this, arguing that science is not only value-laden in the sense described above, but that values of a broader sort-including social and ethical values-also legitimately influence hypothesis appraisal. While many different arguments for this view have been given-including arguments from underdetermination (e.g., Biddle 2013a; Howard 2006; Kourany 2003; Longino 1990, 2002), and concept formation (e.g., Biddle 2016, Dupré 2007, Elliott 2011; Ludwig 2016) - one of the most discussed of late is the argument from inductive risk (e.g., Churchman 1948; Douglas 2000; Elliott 2011; Elliott and Richards 2017; Hempel 1965; John 2015; Rudner 1953; Wilholt 2009, 2013). According to the classical conception, inductive risk is understood as the risk of wrongly accepting (or rejecting) a hypothesis on the basis of evidence (Churchman 1948, Hempel 1965, Rudner 1953). Hypothesis acceptance (or rejection) presupposes ethical value judgments, because there is always some possibility of being wrong (i.e., of accepting a false hypothesis or rejecting a true hypothesis), and being wrong brings different consequences (including moral consequences) for different parties. Consider, for example, hypothesis $H$, which states that exposure to dosage $D$ of pesticide $P$ increases the risk of cancer in human beings. Wrongly accepting $H$ will have consequences for many stakeholders, but those consequences will be particularly significant to industries that profit from the sale of $P$. Alternatively, rejecting $H$ if $H$ is true will also have consequences for many stakeholders, but those consequences will be particularly significant to individuals who are exposed to $P$ at $D$ (e.g., agricultural laborers). In determining how much evidence is enough to accept (or reject) $H$, scientists presuppose value judgments about the various possible consequences of being wrong. In this way, the acceptance (or rejection) of hypotheses on the basis of statistical evidence presupposes ethical value judgments. ${ }^{8}$

Beginning with Douglas (2000), a number of recent scholars have expanded the concept of inductive risk far beyond how it was employed by Churchman, Hempel, and Rudner. On this expanded account, inductive risk is not merely the risk involved in accepting or rejecting a hypothesis on the basis of evidence; rather, there is inductive risk "throughout the scientific process" (Douglas 2000, 563). There are, however, significant problems with this expansion of the concept of inductive risk (Biddle 2016; Biddle and Kukla 2017). ${ }^{9}$ There are a variety of epistemic risks - or risks of error-throughout the scientific process, but these epistemic risks can be very different from one another, and the strategies for managing these risks can be variegated as well. Inductive risk is one type of epistemic risk, but there are many others, and theories of the role of values and interests in science should account for this. For example, a toxicology study might employ an inappropriate model organism-one that obscures rather

\footnotetext{
${ }^{8}$ In this paper, I assume that considerations of inductive risk are sufficient to show that the ideal of value free science is unattainable. See Wilholt (2009) for an especially forceful presentation of the argument.

${ }^{9}$ As I understand it, the main point for which Douglas (2000) argues is that values operate throughout the scientific process. On this point, I agree with her. Where I disagree is with the claim that there is inductive risk throughout the scientific process.
} 
than illuminates the effects that a substance might have on human beings, thereby raising the probability of a particular type of error (e.g., Wilholt 2009). Or a medical community might adopt overly broad diagnostic criteria for a disease, which impedes the development of treatments for that disease (e.g., Biddle 2016; Biddle and Kukla 2017; Kukla 2017). Neither of these risks is best thought of as inductive risk; neither is a mistake made in inferring a hypothesis from statistical evidence. In the former case, the mistake is the choice of a particular model organism, which ultimately affects the data itself, as different model-organism choices will yield different data sets. In the latter case, the mistake is in the conceptualization and operationalization of the disease, which affects any investigation that employs that disease concept (e.g., an investigation of potential treatments for the disease). Both, however, are important epistemic risks, and both must be managed in light of the values and interests. An important topic in research on science and values is to investigate more fully the various types of epistemic risk, how they relate to one another, and how they might be managed. The proceeding examination of epistemic risks in research on GM crops is a step in this direction.

In the case of GM crops, of course, the object of evaluation is not a theory but rather a technology. Still, there are many who hold that GM crops can be evaluated in a value-free manner, because they believe that (1) there is only one relevant evaluative criterion for GM crops-e.g., health and safety-and (2) determinations of health and safety risks are scientific matters that can be decided in a value free manner. I will evaluate each of these claims in turn and show that, in both cases, there are important epistemic risks that must be managed in light of values and interests and that disagreements in the GMO debate often stem from disagreements over these values.

3. Is Health and Safety the Only Relevant Criterion? A significant (and often unstated) point of contention in the GMO debate concerns the range of risks that are relevant to the debate. Critics of GMOs, for example, tend to have a broad range of concerns, including health and safety risks (e.g., allergenicity), risks to the environment (e.g., evolution of herbicide and/or pesticide tolerant plants or animals), and legal and socio-economic risks (e.g., accidental flow of GM seeds onto organic farms, heavy-handed use of patent infringement lawsuits). ${ }^{10} \mathrm{GMO}$ proponents, on the other hand, tend to adopt a much narrower conception of risk. Some argue-or, more commonly, assume - that health and safety is the only relevant criterion for evaluating GM crops. ${ }^{11}$ For example, Mark Lynas, writing for the Cornell Alliance for Science, asserts that "the GMO debate is over," supporting this statement by referencing a 2016 National Academies report, which found "no substantiated evidence that foods from GE crops were less safe than foods from non-GE crops" (Lynas 2016). On this way of framing the issue,

\footnotetext{
${ }^{10}$ See Hicks and Millstein (2016) for a discussion of non-health-and-safety issues.

${ }^{11}$ For discussions of the predominance of the health-and-safety framing, see Hicks (in press), Nestle (2010), and Thompson (2010). By "health and safety risks," I mean risks of direct harm from consumption of GM crops by humans or non-target species (e.g., butterflies). I define health and safety risks in terms of direct harms from consumption to distinguish from cases of indirect biophysical harm - for example, nutritional deficiencies that result from socioeconomic harms that can be traced to the spread of a new technology.
} 
the GMO debate is nothing more than a debate over health and safety. Other proponents maintain that the only risks relevant to the debate are those that are "inherent to genetic engineering." Saletan (2015), for example, argues that environmental and socio-economic risks are irrelevant to the GMO debate, because they are "not... fundamentally about genetic engineering." On this view, the only legitimate question that participants in debates over GM crops may ask is: Are there risks associated with GM crops that are inherent to genetic engineering?

Is it impermissible to evaluate GMOs according to a broad range of criteria? Is it required that GMOs be evaluated according to a narrow conception of risks? I will argue that it is not, beginning by examining more closely what it means for a risk to be inherent to genetic engineering. This question is typically left unanswered by those who dismiss risks that purportedly fall outside of this category. I take it that if we define risk in terms of a probability of harm, then a sufficient condition for a risk being inherent to genetic engineering is that there is some part of the technological process of genetic engineering that causally necessitates an increase in the probability of that harm. Thus, for example, if the GM process involved the use of antibiotic resistant genes as markers, and if these genes raised the probability of antibiotic resistance in humans, then this risk would be inherent to genetic engineering, or at least to this method of genetic engineering. On the other hand, socio-economic risks resulting from the use or abuse of patents or patent licenses by seed companies would not be risks inherent to genetic engineering, as there is nothing in the GM process that causally necessitates the patenting of GM crops.

The claim that the only legitimate criticisms of GM crops are those that pertain to risks inherent to $\mathrm{GM}$ is problematic on a number of grounds, but the most important (and, to my mind, the most straightforward) is that it is legitimate to evaluate technologies on the basis of their intended consequences. If GM crops are designed for particular uses, and if those intended uses raise the probability of harm, then it is perfectly legitimate to criticize the crops on those grounds-even if the intended uses are not causally necessitated by the technological process of genetic engineering. ${ }^{12}$

Consider, for example, the risk that the development and dissemination of some GM crops will lead to increases in patent infringement and breach of contract lawsuits against farmers - and, more generally, to the consolidation of power over agricultural research, products, and methods in the hands of a few multinational corporations. ${ }^{13}$ This is not a risk inherent in genetic engineering; the process of GM does not causally necessitate the patenting

12 In my view, actions can be evaluated not only on the basis of their intended consequences, but also on the basis of consequences that are either foreseen or foreseeable. For the purposes of this argument, however, I need only the claim that actions can be evaluated on the basis of their intended consequences. The general point that it is legitimate to evaluate GM crops on the basis of their foreseen or foreseeable consequences-even if those consequences are not causally necessitated by the GM process - has been made by a number of others, including Lacy (2005).

${ }^{13}$ See Biddle (2014), Hicks and Millstein (2016), Kloppenburg (2004), and Pechlaner (2012) for discussions of patenting and licensing of GM seeds. 
and licensing of crops by seed companies. But there is no doubt that an important reason why companies develop GM crops is because they can be patented and licensed in ways that control the kinds of access that users are legally permitted to have. Patent infringement and breach of contract lawsuits are intended consequences of the development and dissemination of these technologies; GM crops were designed in part for this purpose, and as a result, it is perfectly legitimate to criticize them on these grounds.

One might object to the preceding argument by claiming that, when commentators criticize GM crops, they are attempting to argue that GM crops as a class, or GM crops as such, are problematic. As a result, if their arguments are to succeed, they must show that there are risks inherent to genetic engineering, as showing that there are other types of risks (not inherent to $\mathrm{GM}$ ) does not establish that there are risks of GM crops as such. In response, this objection might succeed against arguments directed to GM crops as a class, but it does not succeed against criticisms of particular GM crops for the particular ways in which they are used-and there are many criticisms that fall into this latter category. To take just one example, consider the criticism of golden rice by the Southeast Asia Regional Initiatives for Community Empowerment (SEARICE), an activist group based in the Philippines:

"the issue on GMO is not on genetic engineering per se, but on how this has been used and is being used to wrest control and access over the plant genetic resources on which the farmers' over time have been the stewards and innovators.... (SEARICE 2013, 5, emphasis in original)

In this criticism, SEARICE makes it explicit that it is not opposed to GM crops as such, but rather to the ways in which particular GM crops are being used. ${ }^{14}$ These kinds of criticisms need notand often do not-result from bias, ignorance, and/or dishonesty; they are not necessarily antiscientific, and indeed are often entirely legitimate.

From the preceding discussion, we can conclude that a narrow conception of risk is not required; it is perfectly legitimate to evaluate GM crops on the basis of environmental, legal, and socio-economic risks. The argument that it is only legitimate to criticize GM crops on the basis of risks inherent to genetic engineering does not succeed. It is legitimate to criticize GM crops, at the very least, on the basis of their intended consequences, and some of these consequences are legal and socio-economic. From this, we can conclude that it is not the case that health and safety concerns are the only legitimate concerns that one might have.

This discussion also relates in important ways to the discussions of values in science in the previous section -in particular to Kuhn's argument that evaluative criteria in science can be interpreted and weighted differently with respect to one another. Just as scientists adjudicating theories might legitimately assign different weights to different evaluative criteria, so scientists, engineers, regulators, policy makers, and others might legitimately assign different weights to the different kinds of risks associated with GM crops. There is nothing anti-scientific about emphasizing environmental, legal, socio-economic, and other kinds of risks that fall outside of

\footnotetext{
${ }^{14}$ See Biddle (2017) for a discussion of SEARICE's criticisms of golden rice and, more generally, an argument against evaluating GM crops as a class.
} 
the health and safety category. How one weighs the importance of different types of concerns is ultimately a question of values.

\subsection{Framing Risks as a Type of Epistemic Risk}

Different ways of framing the problem of GM crops involve epistemic risk. To see this, let me first make a few terminological notes. While the term 'frame' is used in many ways, I use it here to mean an implicit or explicit characterization of a problem, including (among other things) a specification of bounds of the problem-what falls under its scope and what falls outside of it. ${ }^{15}$ By 'ethical risk,' I mean risk of harm in the broadest sense, and by 'epistemic risk,' I mean risk of error in the broadest sense. The concepts of ethical risk and epistemic risk, and their relations to one another, are discussed more fully in Biddle and Kukla (2017). The use of GM crops poses various ethical risks-including health and safety risks, environmental risks, and socio-economic risks - and including (or excluding) any of these risks in a characterization of the problem of GM crops amounts to different ways of framing the problem. As we have seen, many commentators frame it narrowly, including only health and safety risks. This way of framing the problem involves epistemic risk in a very straightforward way-it can inhibit investigations of other risks, which in turn can lead to selective ignorance or error. ${ }^{16}$ In particular, it can lead to the failure to accept significant truths that would have otherwise been accepted, had those questions been investigated more fully. ${ }^{17}$ More generally, framing a problem in any way will affect decisions about which sorts of evidence is relevant to that problem; these decisions will impact the distribution of investigative resources, which in turn will impact the ways in which those investigations balance the risks of false positives, false negatives, and failure to generate results at all.

The tendency to frame the problem solely in terms of health and safety likely contributes to selective ignorance of non-health-and-safety risks. Consider, for example, the effects of patents and patent licenses on GM crop research. All GM crops are patented, and standard patent licenses prohibit others from researching those crops. According to standard Monsanto license agreements, a grower "may not plant and may not transfer to others for planting any Seed that the grower has produced containing patented Monsanto Technologies

\footnotetext{
${ }^{15}$ See Hoffmann (2011) for a discussion of framing in the context of conflict management. Hoffmann distinguishes broadly between 'semiotic framing' and 'cognitive framing,' where the former is the process of producing signs and the latter the process of interpreting signs. He further distinguishes between two types of semiotic framing: 'boundary setting,' which indicates what falls under an issue and what doesn't, and 'meaning construction,' which indicates the meanings of the things that fall under the issue. I use the term framing primarily in the sense of boundary setting, though as Hoffmann argues, boundary setting is intertwined with cognitive framing, as how one defines a problem is related to how one interprets, or 'makes sense' of, that problem.

${ }^{16}$ The term "selective ignorance" is due to Elliott (2012), and the concept of selective ignorance comes from Proctor's introduction to Proctor and Schiebinger (2008).

${ }^{17}$ The concept of significant truth is developed by Kitcher (2001).
} 
for crop breeding, research, or generation of herbicide registration data" (Monsanto Company 2008, emphasis added). Other seed companies have similar restrictions (Scientific American 2009). In 2009, a group of entomologists from public U.S. universities issued a statement that license restrictions were "inhibiting public scientists from pursuing their mandated role on behalf of the public good unless the research is approved by industry." As a result of these restrictions, they argued, "no truly independent research can be legally conducted on many critical questions regarding the technology...." ${ }^{18}$ Since then, some patchwork agreements have loosened restrictions, but patent licenses still place significant impediments to research for many scientists (Biddle 2014; Glenna et al. 2015; Hicks and Millstein 2016). These impediments raise a series of important questions, such as: Have patent licenses on GM crops impacted research activity? If so, how? And to what extent? These are questions that are amenable to empirical investigation, and yet they have received very little attention. ${ }^{19} \mathrm{~A}$ plausible explanation for this lack of attention is that, on a narrow health and safety framing, evidence about the effects of patent licenses on research is simply not relevant to the GMO debate. The incentive to investigate these questions is greatly reduced on a narrow health and safety framing, and given these reduced incentives, risks of ignorance or error is increased. ${ }^{20}$

Framing is a necessary activity-the investigation of a problem requires that the problem be defined and delimited-and the fact that framing involves epistemic risk has not been emphasized in discussions of the role of values in science ${ }^{21}$ or the GMO debate. ${ }^{22}$ Perhaps one explanation for why philosophers of science have not emphasized this stems from the

${ }^{18}$ The comment can be found at: http://www.regulations.gov/\#!documentDetail;D=EPA-HQOPP-2008-0835-0017. Accessed April 20, 2017.

${ }^{19}$ To my knowledge, Glenna et al. (2015) is the only empirical study of questions like this. They surveyed entomologists who conduct research on GM crops; while their study is limited, they do find some evidence for concern-such as that 31\% of respondents report that their research on GM crop efficacy or environmental impact has been "hindered by an industry partner" (Glenna et al. 2015, 161). However, further investigations are required to get a clearer picture of the impact of patents and patent licenses on GM crop research.

${ }^{20}$ For investigators who initially assume that patent licenses do not restrict research activity, the failure to investigate this question might contribute to false negatives. For those who have never considered the question in the first place, it contributes to continued ignorance.

${ }^{21}$ Some have argued for a related claim, namely that the choice of problems to address can affect decisions of which hypotheses to accept, as prior decisions about which projects to pursue affects the data sets available at a given time, as well as the space of potential solutions that a scientist might consider. Okruhlik (1994) and Elliott and McKaughan (2009) given arguments similar to this. The point that I am making here is related but different. I agree that decisions to investigate one set of problems rather than another involves epistemic risk, but I am also arguing that the way in which a problem is framed in the first place involves epistemic risk.

${ }^{22}$ Several commentators on the GMO debate have emphasized the consequences of a narrow health-and-safety framing on ethics, politics, and regulation (e.g., Hicks in press; Nestle 2010; Thompson 2010), but none to my knowledge has emphasize the consequences for research. 
expanded account of inductive risk. On this expanded account, there is a tendency to view all relevant risks internal to scientific research as inductive risks. But the risk involved in framing a problem is clearly not an inductive risk. While the differences between the two merit further exploration, one clear difference is that inductive risk is necessarily a type of inferential risk, whereas framing risk is not. To frame a problem in a particular way is not (necessarily) to develop a hypothesis about how it should be framed and then accept (or reject) that hypothesis on the basis of evidence. There are a variety of factors that might lead a researcher to frame a problem in a particular way; in many cases, framing occurs unconsciously, without consideration of evidence at all. Despite the fact that framing risk is distinct from inductive risk, framing does involve epistemic risk, in that it involves tradeoffs between risks of false positives, false negatives, and failure to obtain results. The tendency to view all relevant risks as inductive risks might, in cases such as this, serve to mask important epistemic risks that are distinct from inductive risk.

That framing involves epistemic risk is a point that deserves to be made, particularly given how important framing is in the debate over GM crops (as well as in other debates). One of the points at issue in this debate is which questions legitimately fall under the umbrella of the GMO debate; given the importance of boundary work in this debate, it is important to emphasize that framing not only has implications for ethics and politics, but also for epistemology. This latter claim has not been emphasized in philosophical discussions of the role of value in science.

4. On Determining Safety Value Free. Suppose that we put aside the issue of how narrowly or broadly to frame the GMO problem and focus exclusively on health and safety risks. Many argue that the determination of health and safety risks can and should be done in a value neutral manner. For example, the United Nations Food and Agriculture Organization's “Science for Safe Food" strategy demands that scientific advice on food safety be based on "sound science" that is "neutral and independent." ${ }^{23}$ Furthermore, many hold that such neutral and independent research has already been conducted, and that the result is that GM crops (at least those that are currently sold on the market) are at least as safe as those produced using traditional methods (e.g., Blancke et al. 2015; Bourlaug 2000). A closer examination of the question of health and safety risks, however, shows that there are still significant spaces for rational disagreement, and value judgments play an important role in explaining disagreement within these spaces.

It is reflective of the polarized nature of the debate that, not only do published studies on health and safety impacts of GM crops arrive at different conclusions, but so also do systematic reviews of those studies. According to one review, "the studies reviewed present evidence to show that GM plants are nutritionally equivalent to their non-GM counterparts and can be safely used in food and feed" (Snell et al. 2012, 1134). Another review, however, finds that the number of research groups finding significant health and safety risks is roughly equal to

${ }^{23}$ See, for example: <http://www.fao.org/3/a-i2797e/i2797e06.pdf>. Accessed November 19, 2017. 
the number indicating no such risks (Domingo and Bordonaba 2011). Yet another concludes that the overall results are inconclusive:

it appears that there is no adverse effect of GM crops observed for many species of animal in acute or short-term feeding studies, but serious debate still surrounds longterm and multigenerational feeding studies.... Therefore, long-term and multigenerational feeding studies are clearly necessary to further investigate on this important issue (Zhang and Shi 2011, 1056).

More generally, Krimsky (2015) searched PubMed and Web of Science databases for systematic reviews on health-and-safety impacts of GMOs between 2008 and 2014; eight reviews were published during this period, and they differ significantly in their conclusions. There are systematic reviews that fit into the following three categories: (1) those that find evidence for significant health and safety risks, (2) those that find no evidence for significant health and safety risks, and (3) those that come to no general conclusion but call for more testing.

How can systematic reviews of scientific articles arrive at such diverse conclusions? There are a variety of factors that help to explain this diversity, including different choices of endpoints (e.g., Snell et al. investigate health impact generally, whereas Zhang and Shi focus on animal reproduction), determinations of which studies to include in the review, and weightings of the importance of these studies. However, one of the most important sources of controversy regarding health and safety risks concerns the question of how long animal studies need to be in order detect chronic, long-term risks. The current standard is 90-day feeding studies in rodents; this standard has been adopted by a number of scientific and regulatory bodies, including the European Food Safety Authority (EFSA) (DeFrancesco 2013). By and large, these studies have not found significant health-and-safety risks resulting from consumption of GMOs. At the same time, the 90-day standard is a convention, and it is unclear whether the convention is well-suited for obtaining results that bear on long-term human health. According to Martijn Katan, emeritus professor of nutrition at Vrije Universiteit Amsterdam, "few toxicologists ever stop to think whether such [90-day] animal tests really predict the effect in humans, because if we start to doubt this dogma, the whole system collapses" (quoted in DeFrancesco 2013, 797). The European Union has called for two-year carcinogenicity studies (DeFrancesco 2013, 797), and a number of scientists who investigate health and safety risks in GMOs have recommended that more long-term studies be conducted (e.g., Zhang and Shi 2011).

One of the studies at the center of this debate is a controversial article by Séralini et al. (2012) that was later retracted. Noting that long-term studies on animals had not been conducted, Séralini et al. examined the effects of consumption of Roundup-tolerant GM maize (including maize cultivated with and without Roundup) on rats over a 2-year period, which is roughly the lifespan of the rats. The results of the investigation included higher incidence of mortality (2-3 fold) in the treated groups, more rapid morality, and higher numbers of tumors. The study included 10 rats in each group, which is below the standard for carcinogenesis studies (50/group). However, the authors stated explicitly that their study was not intended to test for carcinogenicity (Séralini et al. 2012, 4222). Perhaps most importantly, Séralini et al. hoped this preliminary study would shed light on the question of whether larger, long-term studies on GM crops should be conducted regularly. 
Immediately after publication of the paper in Food and Chemical Toxicology (FCT), the journal was flooded with criticisms and demands that the paper be retracted. After an extended debate-including a point-by-point response to criticisms by Séralini et al. and an editorial by the journal's editor-in-chief that appear to back the original article-the editor-inchief retracted the paper. ${ }^{24}$ However, the editor-in-chief was explicit and unequivocal that there was "no evidence of fraud or intentional misrepresentation of the data.... Ultimately, the results presented (while not incorrect) are inconclusive." ${ }^{25}$ The decision to retract the paper is controversial. The "inconclusiveness" of a paper is not typically regarded as grounds for retraction; for example, the Committee on Publication Ethics does not consider this to be sufficient grounds for retraction (COPE 2009). ${ }^{26}$ Moreover, the data presented in the paper was not called into question by the editor-in-chief, and the data is arguably very valuable, as it constitutes strong grounds for the claim that larger, long-term studies should be conducted. As it stands, the data is not only ignored by many GMO proponents; the retraction is also used as a rhetorical weapon to suggest that the only way to question the safety of GM foods is to manufacture data.

Upon examination of the divergence in conclusions reached by the various systematic reviews of health and safety risks, it is clear that there is still significant disagreement among the relevant experts in the field. The question of how long animal studies need to be in order to assess long-term risks is not, at this point, answerable conclusively by the available evidence. Answers to this question depend on value judgments concerning the balancing of false positives, false negatives, and failure to generate results. There is nothing irrational or antiscientific in arguing that two-year studies should be conducted.

\subsection{Power Risks as a Type of Epistemic Risk}

There are epistemic risks in research on health-and-safety impacts of GMOs, and it might appear at first glance that-in the case of the question of how long the animal studies should be-the relevant epistemic risks are inductive risks. On further examination, however, the situation is more complex.

Torsten Wilholt has shown that scientific reasoning involves complex tradeoffs between the reliability of positive results (or risks of false positives), the reliability of negative results (or risks of false negatives), and the investigation's power, which he defines as the rate at which an investigation delivers definitive results (Wilholt 2013, 244). In undertaking scientific

${ }^{24}$ See Krimsky (2015) for further discussion.
${ }^{25}$ http://www.sciencedirect.com/science/article/pii/S0278691512005637. Accessed November 19, 2017.

${ }^{26}$ COPE guidelines are that editors should consider retraction if one of the following four conditions are met: "they have clear evidence that the findings are unreliable, either as a result of misconduct... or honest error...; the findings have previously been published elsewhere, without proper crossreferencing, permission, or justification...; it constitutes plagiarism; it reports unethical research" (COPE 2009, also quoted in Krimsky 2015). As acknowledged by the FCT editor-in-chief, Séralini et al. (2012) satisfies none of these conditions. 
investigations, we wish not only to avoid wrongly accepting false hypotheses and wrongly rejecting true hypotheses - we also wish to generate results. For example, in choosing levels of statistical significance, researchers who wish to avoid false positives must at the same time ensure that they do not set their $p$ values too low, as this might raise to unacceptable levels the risks of false negatives and/or of failure to generate results at all. If an investigator set $p$ equal to 0.005 (ten times lower than the conventional standard), and if the investigation failed to yield a statistically significant association, the investigator might conclude that there is no such association-or they might not conclude anything at all and remain in a state of ignorance. Scientific reasoning requires balancing the reliability of positive results, reliability of negative results, and an investigation's power-and under most circumstances, this balancing is done in light of values and interests (Wilholt 2009; 2013). Given this background, one might distinguish between inductive risk (the risk of wrongly accepting or rejecting a hypothesis on the basis of evidence) and power risk (the risk that an investigation does not generate results at all).

As an example, consider the standard 90-day toxicology studies on rodents, and suppose for the sake of argument that the studies involve a sufficiently high number of animals (whatever 'sufficiently high' is, in this case). The reliability of positive results and the reliability of negative results will be impacted by the choice of a $p$ value; lower $p$ values will increase the reliability of positive results and decrease the reliability of negative results, while higher $p$ values will do the opposite. But the debate over trial lengths suggests that there is also significant power risk involved in these trials. There are many experts within the relevant field who interpret negative results not as indicating that GMOs have no significant detrimental long-term health impacts in rodents, but as indicating nothing whatsoever about long-term risks. They remain in a state of ignorance, because they do not believe that 90-day trials are powerful enough (in this case, long enough) to detect chronic long-term health risks. In order for a trial to be sufficiently powerful to generate results about a particular hypothesis, the trial must produce enough evidence, and it must produce evidence of the right sort-that is, evidence that is relevant to the hypothesis in question. In this case, there is significant disagreement among the relevant experts about whether 90-day trials produce evidence that is relevant to long-term health risks in humans. (There might also be questions about whether evidence from animal studies provide evidence relevant to health risks in humans, but I will not consider that issue here.) Thus, 90-day trials involve significant power risk of failing to generate results that are relevant to long-term health risks, and this risk can and often should be distinguished from other types of epistemic risk.

The importance of distinguishing between reliability of positive results, reliability of negative results, and power is also evident from the divergent conclusions reached by systematic reviews of research on health and safety risks of GM foods. Recall that the reviews fit into the following three categories: (1) those that find evidence for significant health and safety risks (positive result), (2) those that find no evidence for significant health and safety risks (negative result), and (3) those that come to no general conclusion but call for more testing (no result). Researchers must make tradeoffs between risks of false positives, false negatives, and failure to generate results, and these tradeoffs reflect value judgments about the costs of different types of error for different stakeholders. Given that these value 
judgments can plausibly be made in different ways, there is space for rational disagreement in the assessment of health and safety risks of GM crops.

5. Conclusions: Values, Epistemic Risks, and Varieties of Disagreement. I have argued that criticisms of GM crops are not necessarily "anti-science." There are significant spaces for rational disagreement in evaluations of the risks of GM crops, and differences in values play important roles within these spaces. There are a number of reasons why it is important to recognize this. First, the GMO debate has important implications for public policy making, agricultural practice, health and environmental impact, and many other areas. The technology of genetic engineering is promising, and it could lead to important agricultural developments, especially given the growing challenges of adapting to global climate change. At the same time, many GM crops impose significant risks upon farmers and other members of the public; some of these might be health and safety risks, but many are legal, socio-economic, and otherwise outside of a narrow health-and-safety framework. Given the importance of the GMO debate for multiple stakeholders, it is crucial that the debate be conducted in an intelligent fashion, and recognition of the roles and impacts of values and interest in GMO research could help to improve the character and quality of the debate.

There is a tendency on both sides of the debate to interpret the controversy in terms of what one might call dirty disagreement. By dirty disagreement, I mean disagreement that results from ignorance, bias, irrationality, or dishonesty on the part of one or more parties to the disagreement. Dirty disagreement is not rational disagreement; in this case, at least one party to the disagreement argues dishonestly or makes a mistake (for example, by ignoring relevant evidence or committing inferential errors). There are many within the GMO debate who interpret the controversy in these terms - that is, they believe that those who disagree with them do so as a result of ignorance, bias, irrationality, or dishonesty. There are some disagreements that are accurately characterized in these terms. There are even some particular disagreements within the GMO debate that are accurately characterized in these terms. But as argued, the overall debate is not accurately characterized as such, as there are significant spaces within debate for rational disagreement.

The GMO controversy is more accurately characterized in terms of deep disagreement. Lynch (2010) defines deep disagreement in terms of disagreement over which methods are most reliable in a given domain (where reliability is understood in terms of production of true beliefs). As the preceding discussion shows, however, there can be more to deep disagreement than this. Deep disagreement can involve disagreement about what kinds of evidence are relevant to a given hypothesis, and while disagreements over what counts as evidence can sometimes result from disagreements over methods, they can also result from other sorts of disagreements. As in the case of the GMO debate, disagreement over how a problem should be framed can lead to disagreement about what kinds of evidence is relevant to that problem. Furthermore, the distinction between reliability and power shows that there can be rational disagreement not only over which methods are most reliable, but also about whether a particular method produces evidence that is relevant to a given hypothesis. This suggests a broader characterization of deep disagreement-one that includes not only disagreements over 
which epistemic standards are most reliable, but also about which types of evidence count as evidence for a given hypothesis. ${ }^{27}$

The notion of deep disagreement-particularly as it relates to controversies in science and technology-requires further investigation, and the question of how differences in values affect deep disagreement is of crucial importance. But in addition to developing a more sophisticated philosophical account of deep disagreement, it is also important that philosophers of science, scholars of science and technology studies, and others contribute to controversies in science and technology by emphasizing that rational disagreement is not only possible, but pervasive. Doing this could help significantly to improve communication and raise mutual understanding.

${ }^{27}$ Hicks (2015) discusses deep disagreement in terms of disagreement over what counts as evidence. 


\section{References}

Biddle, Justin B. 2013. "State of the Field: Transient Underdetermination and Values in Science." Studies in History and Philosophy of Science 44: 124-133.

Biddle, Justin B. 2014. "Can Patents Prohibit Research? On the Social Epistemology of Patenting and Licensing in Science." Studies in History and Philosophy of Science 45: 14-23.

Biddle, Justin B. 2016. “Inductive Risk, Epistemic Risk, and Overdiagnosis of Disease." Perspectives on Science 24(2): 192-205.

Biddle, Justin B. 2017. "Genetically Engineered Crops and Responsible Innovation." Journal of Responsible Innovation 4: 1-17.

Biddle, Justin B. and Rebecca Kukla. 2017. "The Geography of Epistemic Risk." In Exploring Inductive Risk: Case Studies of Values in Science, ed. K. Elliott and T. Richards, 215-237. Oxford: Oxford University Press.

Blancke, Stefaan, Frank Van Breusegem, Geert De Jaeger, Johan Braeckman, and Marc Van Montagu. 2015. "Fatal Attraction: The Intuitive Appeal of GMO Opposition." Trends in Plant Science 20: 414-418.

Borlaug, Norman. 2000. "Ending World Hunger. The Promise of Biotechnology and the Threat of Antiscience Zealotry." Plant Physiology 124: 487-490.

COPE (Committee on Publication Ethics). 2009. "Retraction Guidelines."

http://publicationethics.org/files/retraction\%20guidelines.pdf. Accessed November 19, 2017.

DeFrancesco, Laura. 2013. "How Safe Does Transgenic Food Need to Be?" Nature Biotechnology 31: 794-802.

Domingo, J. L., and J. G. Bordonaba. 2011. "A Literature Review on the Safety Assessment of Genetically Modified Plants." Environment International 37 (4): 734-42.

Douglas, Heather. 2000. "Inductive Risk and Values in Science." Philosophy of science 67: 559579.

Dupré, John. 2007. "Fact and Value." In Value-Free Science? Ideals and Illusions, ed. H. Kincaid, J. Dupré, and A. Wylie, 21-41. Oxford: Oxford University Press.

Elliott, Kevin. 2011. Is a Little Pollution Good for You? Incorporating Societal Values in Environmental Research. New York: Oxford University Press.

Elliott, Kevin. 2013. "Selective Ignorance and Agricultural Research." Science, Technology, \& Human Values 38: 328-350.

Elliott, Kevin and Daniel McKaughan. 2009. "How Values in Scientific Discovery and Pursuit Alter Theory Appraisal." Philosophy of Science 76: 598-611.

Elliott, Kevin and Ted Richards, eds. 2017. Exploring Inductive Risk: Case Studies of Values in Science. New York: Oxford University Press.

Glenna, Leland, John Tooker, Rick Welsh, and David Ervin. 2015. "Intellectual Property, Scientific Independence, and the Efficacy and Environmental Impacts of Genetically Engineered 
Crops." Rural Sociology 80: 147-72.

Goldenberg, Maya. 2016. "Public Misunderstanding of Science? Reframing the Problem of Vaccine Hesitancy." Perspectives on Science 24: 552-581.

Guillemaud, Thomas, Eric Lombaert, and Denis Bourguet. 2016. "Conflicts of Interest in GM Bt Crop Efficacy and Durability Studies." PLoS ONE 11(12): e0167777.

doi:10.1371/journal.pone.0167777

Hicks, Dan. 2015. "Epistemological Depth in a GM Crops Controversy." Studies in History and Philosophy of Biological and Biomedical Sciences 50: 1-12.

Hicks, Dan. in press. "Genetically Modified Crops, Inclusion, and Democracy." Perspectives on Science.

Hicks, Dan and Roberta Millstein. 2016. "Genetically Modified Organisms: Non-Health Issues." Encyclopedia of Food and Agricultural Ethics (pp. 1-11). Dordrecht: Springer.

Hoffmann, Michael H. G. 2011. “Analyzing Framing Processes in Conflicts and Communication by Means of Logical Argument Mapping." In W. A. Donohue, R. G. Rogan, \& S. Kaufman (Eds.), Framing Matters: Perspectives on Negotiation Research and Practice in Communication (pp. 136-164). New York, NY: Peter Lang.

Howard, Don A. 2006. "Lost Wanderers in the Forest of Knowledge: Some Thoughts on the Discovery-Justification Distinction." In J. Schickore \& F. Steinle (Eds.), Revisiting discovery and justification: Historical and philosophical perspectives on the context distinction, (pp. 3-22). Dordrecht: Springer.

John, Stephen. 2015. "Inductive Risks and the Contexts of Communication." Synthese 192: 7996.

Kitcher, Philip. 2001. Science, Truth, and Democracy. New York: Oxford University Press.

Kitcher, Philip. 2011. Science in a Democratic Society. Amherst, NY: Prometheus Books.

Kloppenburg, Jack. 2005. First the Seed: The Political Economy of Plant Biotechnology. Madison, WI: University of Wisconsin Press.

Kourany, Janet. 2010. Philosophy of Science after Feminism. Oxford: Oxford University Press.

Krimsky, Sheldon. 2015. "An Illusory Consensus Behind GMO Health Assessment." Science, Technology, \& Human Values 40: 883-914.

Kuhn, Thomas. 1977. "Objectivity, Value Judgment, and Theory Choice." In The Essential Tension: Selected Studies in Scientific Tradition and Change (pp. 320-339). Chicago: University of Chicago Press.

Kukla, Rebecca. 2017. "Infertility, Epistemic Risk, and Disease Definitions." Synthese doi:10.1007/s11229-017-1405-0

Kupferschmidt, Kai. 2013. “Activists Destroy 'Golden Rice' Field Trial.” Science. August 9. < http://www.sciencemag.org/news/2013/08/activists-destroy-golden-rice-field-trial>. Accessed February 27, 2017. 
Lacey, H. 2005. Values and Objectivity in Science: The Current Controversy Over Transgenic Crops. Lexington: Lexington Books.

Lewandowsky S., G. E. Gignac, K. Oberauer. 2013. "The Role of Conspiracist Ideation and Worldviews in Predicting Rejection of Science." PLOS ONE 8(10): e75637. doi:10.1371/journal.pone.0075637

Longino, Helen. 1990. Science as Social Knowledge: Values and Objectivity in Scientific Inquiry. Princeton: Princeton University Press.

Longino, Helen. 1996. "Cognitive and Non-Cognitive Values in Science: Rethinking the Dichotomy." In Feminism, Science, and the Philosophy of Science, ed. L. H. Nelson and J. Nelson, 39-58. Dordrecht: Kluwer.

Longino, Helen. 2002. The Fate of Knowledge. Princeton: Princeton University Press.

Lynas, Mark. 2016. "The GMO Debate is Over."

https://allianceforscience.cornell.edu/blog/mark-lynas/gmo-safety-debate-over. Accessed November 17, 2017.

Lynch, Michael. 2010. "Epistemic Circularity and Epistemic Incommensurability." In Social Epistemology, ed. Adrian Haddock, Alan Millar, and Duncan Pritchard, 262-277. Oxford: Oxford University Press.

McMullin, Ernan. 1983. "Values in Science." In PSA 1982, Vol. 2, ed. P. D. Asquith and T. Nickles, 3-28. East Lansing, Michigan: Philosophy of Science Association.

Millstein, Roberta L. 2015. "GMOs? Not So Fast." The Common Reader: A Journal of the Essay. May 8. <https://commonreader.wustl.edu/c/gmos-not-so-fast/>. Accessed August 1, 2016.

Monsanto Company. 2008. “2008 Monsanto Technology/Stewardship Agreement.” Available at <http://www.monsanto.com/SiteCollectionDocuments/tug_sample.pdf>. Accessed April 20, 2017.

Monsanto Company. 2012. "Do GM Crops Increase Yield?" Available at <http://www.monsanto.com/newsviews/pages/do-gm-crops-increase-yield.aspx>. Accessed March 28, 2017.

Mooney, Chris. 2014. "Stop Pretending that Liberals are Just as Anti-Science as Conservatives." Mother Jones. Available at <http://www.motherjones.com/environment/2014/09/left-sciencegmo-vaccines>. Accessed February 23, 2017.

NASEM (National Academies of Sciences, Engineering, and Medicine). 2016. Genetically Engineered Crops: Experiences and Prospects. Washington, DC: The National Academies Press. doi: $10.17226 / 23395$.

National Research Council (NRC). 2002. Environmental Effects of Transgenic Plants: The Scope and Adequacy of Regulation. Washington, DC: The National Academies Press.

Navin, Mark. 2016. Values and Vaccine Refusal: Hard Questions in Epistemology, Ethics and Health Care. New York: Routledge. 
Nestle, Marion. 2010. Safe Food: The Politics of Food Safety, updated and expanded edition. Berkeley: University of California Press.

Nuffield Council on Bioethics. 1999. Genetically Modified Crops: The Ethical and Social Issues. Available at: <https://nuffieldbioethics.org/wp-content/uploads/2014/07/GM-crops-fullreport.pdf>. Accessed April 18, 2017.

Nuffield Council on Bioethics. 2003. The Use of Genetically Modified Crops in Developing Countries. Available at: <https://nuffieldbioethics.org/wp-content/uploads/GM-CropsDiscussion-Paper-2003.pdf>. Accessed April 18, 2017.

Okruhlik, Kathleen. 1994. "Gender and the Biological Sciences." Canadian Journal of Philosophy 24 (supplementary volume 20 ): 21-42.

Pechlaner, Gabriela. 2012. Corporate Crops: Biotechnology, Agriculture, and the Struggle for Control. Austin, TX: University of Texas Press.

Pew Research Center. 2016. "The New Food Fights: U.S. Public Divides Over Food Science.” Available at <http://assets.pewresearch.org/wpcontent/uploads/sites/14/2016/12/19170147/PS_2016.12.01_Food-Science_FINAL.pdf>. Accessed February 11, 2017.

Proctor, Robert and Londa Schiebinger. 2008. Agnotology: The Making and Unmaking of Ignorance. Stanford: Stanford University Press.

Rudner, Richard. 1953. "The Scientist Qua Scientist Makes Value Judgments." Philosophy of Science 20(1): 1-6.

Saletan, William. 2015. "Unhealthy Fixation." Slate. Available at <http://www.slate.com/articles/health_and_science/science/2015/07/are_gmos_safe_yes_the _case_against_them_is_full_of_fraud_lies_and_errors.html>. Accessed February 28, 2017.

Scientific American. 2009. "Do Seed Companies Control GM Crop Research?” Scientific American. https://www.scientificamerican.com/article/do-seed-companies-control-gm-cropresearch/. Accessed November 19, 2017.

Shermer, Michael. 2013. "The Liberals' War on Science." Scientific American. Available at < https://www.scientificamerican.com/article/the-liberals-war-on-science/>. Accessed February 23, 2017.

Snell, C., A. Bernheim, J. B. Berge, M. Kuntz, G. Pascal, A. Paris, and A. E. Ricroch. 2012. "Assessment of the Health Impact of GM Plant Diets in Long- term and Multigenerational Animal Feeding Trials: A Literature Review." Food \& Chemical Toxicology 50: 1134-1148.

Southeast Asia Regional Initiatives for Community Empowerment (SEARICE). 2013. Going Against the Golden Grain: A Primer on Golden Rice. <http://searice.org.ph/wpcontent/uploads/2013/09/GoingAgainstTheGoldenGrain_screen.pdf>. Accessed July 30, 2016. Thompson, Paul B. 2010. Food Biotechnology in Ethical Perspective, $2^{\text {nd }}$ edition. Dordrecht: Springer. 
Wilholt, Torsten. 2009. "Bias and Values in Scientific Research." Studies in History and Philosophy of Science 40: 92-101.

Wilholt, Torsten. 2013. "Epistemic Trust in Science." British Studies in Philosophy of Science 64: 233-253.

Zhang, W. and F. Shi. 2011. "Do Genetically Modified Crops Affect Animal Reproduction? A Review of the Ongoing Debate." Animal 5: 1048-1059. 